\title{
Árboles petrificados, de Amparo Dávila: un ciclo cuentístico en torno a la libertad ${ }^{1}$
}

\author{
Árboles petrificados by Amparo Dávila: a short-story \\ cycle on freedom
}

\author{
José Miguel Sardiñas FernándeZ \\ ORCID: 0000-0001-7975-1824 \\ Universidad Autónoma de San Luis Potosí, México \\ miguel.sardinas@uaslp.mx
}

Resumen:

El libro de cuentos Árboles petrificados (1977), de la narradora mexicana Amparo Dávila (Zacatecas, 1928), parece ser un ciclo cuentístico. Uno de los rasgos que sostienen esa hipótesis es la relación que la mayoría de los protagonistas de sus cuentos establecen con el pasado: esos protagonistas ven el pasado como un refugio ante un presente intolerable. Este artículo tiene como objetivo verificar el carácter de ciclo cuentístico de ese libro y determinar si el pasado finalmente funciona como el refugio que los protagonistas buscan. Para cumplirlo, se basa en las teorías de los ciclos cuentísticos y en la clasificación funcional de los protagonistas de Vladímir Propp (héroes buscadores y héroes víctimas) y de Claude Bremond (roles de agente y paciente). Como resultado del análisis de las categorías de espacio, tiempo, narrador y personajes, concluye que el libro

${ }^{1}$ Este trabajo se realizó con financiamiento del PRODEP (México) bajo la modalidad de "Apoyo a la Incorporación de Nuevos PTC", convenio DSA/103.5/15/6988. 
puede considerarse un ciclo cuentístico y que uno de sus rasgos más relevantes es el género de los protagonistas (son mujeres en su mayoría) y su rol de víctimas o pacientes, que se traduce en un conjunto de personajes mujeres sometidas a situaciones asfixiantes de las cuales tratan de huir hacia el pasado, el cual se convierte en una prisión simbólica. La conclusión muestra la marcada sensibilidad de la autora por la situación de personajes mujeres de diferentes sectores sociales, a pesar de su rechazo explícito a ser considerada una escritora feminista.

\section{Palabras clave:}

cuento mexicano, Amparo Dávila, ciclos cuentísticos, personajes femeninos, sensibilidad feminista.

\section{Abstract:}

Árboles petrificados (1977), a short story collection by Amparo Dávila (Zacatecas, Mexico, 1928), could be considered a short story cycle. One of the features which support this hypothesis is based on the relation established by most of the protagonists, within the book, with their past. These characters think of their past as a refuge, when confronted with an intolerable present. The main purposes of this article are, firstly, to verify if this book is a short story cycle and, secondly, to determine if the past finally functions as the refuge the characters look for. To fulfill these objectives, the theoretical framework combines short story cycle theories with the functional classification of heroes of both Vladimir Propp (seeker-heroes and victim-heroes) and Claude Bremond (agent and patient roles). As a result of the analysis of setting time, narrator and characters in all the short stories of Árboles petrificados (twelve in total), the article concludes that the book works as a cycle and, that one of its most relevant characteristics is the gender and the role of its heroes: most of them are female and, they are victims looking for refuge in their past, which finally becomes a symbolic prison. This conclusion shows Dávila's emphatic empathy to women characters of different social levels, despite her explicit refuse to be considered a feminist woman writer. 
Key words:

Mexican short story, Amparo Dávila, short-story cycles, women characters, feminist sensitivity.

DOI: https://doi.org/10.36798/critlit.vi20.306

Recibido: 06 de agosto de 2019

Aceptado: 19 de febrero de 2020

Árboles petrificados (1977), como los dos libros no misceláneos que le precedieron (Tiempo destrozado, 1959 y Música concreta, 1961) de la narradora y poeta Amparo Dávila (Zacatecas, 1928), parece atravesado por varias líneas de afinidad temática, temporal, espacial y actorial que permiten recorrerlo en distintas direcciones. De hecho, esta perspectiva fue la privilegiada por la recepción inicial de este libro, como puede verse en una de sus reseñas ("la mayoría cae en el dominio del cuento psicológico", "exploran el entorno universal de la mente humana", Reeve 161), ${ }^{2}$ aunque no es la que hasta el momento ha prevalecido, ${ }^{3}$ evidentemente por el desplazamiento de los intereses de la teoría y la crítica literarias, operado

${ }^{2}$ Soy responsable de la traducción de las citas, si no se indica otra cosa.

${ }^{3}$ La mayor parte de los estudios se centra, o bien en el libro Tiempo destrozado, o bien en cuentos tomados de cualquier libro, teniendo en cuenta intereses temáticos o tipos de personajes. Entre los que incluyen cuentos de Árboles petrificados, pueden mencionarse los estudios de Pita (sobre "El último verano" y "El pabellón del descanso", desde una perspectiva feminista no especificada), Frouman-Smith (sobre "Detrás de la reja" y "El último verano", además de "El huésped”, también con marco teórico feminista, en su caso de Gilbert y Gubar), Rivero Romero (sobre "Griselda”), Herrera (sobre "Óscar"), Ortiz Sánchez (colección de artículos independientes, de los cuales el tercero trata sobre "Detrás de la reja", entre otros cuentos), Gutiérrez Piña (sobre "El último verano") y Luna Chávez junto a Díaz Arciniega (sobre "Detrás de la reja” y "Óscar", entre otros cuentos, y su relación con lo siniestro — concepto que no definen- y el sufrimiento). Para una revisión más amplia de la bibliografía crítica sobre Dávila publicada hasta 2016, véase Álvarez Rivera (27-37). 
entre las décadas de 1980 y 1990, hacia cuestiones antropológicas, sociológicas, de género o de recuperación del sujeto autoral. No obstante, esta obra parece ser un conjunto con unidad, como lo han señalado algunos críticos, —Lorenzo y Salazar ("La narrativa" 61-63) mencionan los rasgos góticos, en tanto que Mata (17) afirma que "Árboles petrificados es el libro más sólidamente construido" de los tres publicados hasta 1977 - y puede que también con una organización interna específica. Destacar esa posible característica puede ser pertinente en la medida en que se trata de un ángulo escasamente explorado.

En este caso, el rasgo de afinidad que interesa señalar es la relación que los protagonistas establecen con el tiempo, como dimensión que marca enfáticamente sus vidas: en casi todos los relatos puede observarse una vuelta hacia el pasado, ante un presente insatisfactorio o intolerable. A partir de tal premisa, puede formularse la pregunta que articula esta investigación: ¿es el pasado un refugio a donde los personajes pueden huir de su presente o es un espacio de opresión para ellos? Este artículo tiene, pues, como objetivos generales indagar si Árboles petrificados constituye una unidad - no una miscelánea- - y determinar el valor de la dimensión temporal en los conflictos de sus protagonistas. Para cumplir con esos propósitos, este estudio se apoyará en las teorías de los short story cycles o ciclos cuentísticos, según su denominación más general, y en las clasificaciones funcionales de los personajes de Vladímir Propp (héroes buscadores y héroes víctimas) y de Claude Bremond (roles de agente y paciente). Estas clasificaciones son de larga data, como puede deducirse de las fechas originales de las obras que las propusieron, pero tienen las ventajas de permitir determinar cuándo un personaje es víctima o agresor sobre una base objetiva (mucho más que su caracterización o a veces solo su sexo) y de poder aplicarse con facilidad a un género fuertemente marcado por las acciones, como el cuento, aun cuando se trate de cuentos de autor y no populares, folclóricos o tradicionales. Sus denominaciones son suficientemente descriptivas como para que no sea necesario recurrir a otras más recientes, pero más abstractas y neutras, y basadas en ellas, como la de sujeto de Greimas. 
La metodología que se pondrá en práctica consistirá en examinar componentes del universo de la ficción como el espacio, los tiempos, algunos rasgos de la voz narrativa y los personajes, a fin de detectar posibles afinidades y de descubrir tendencias. Una vez efectuado esto, se pasará a interpretar los valores predominantes, en el nivel del libro, como signo que integra a los cuentos y genera sentidos que son más que la mera suma de sus partes.

Un ciclo cuentístico inicialmente se entendió como "un libro de cuentos unidos de tal forma unos con otros por su autor que la experiencia sucesiva del lector en varios niveles del patrón del conjunto modifica significativamente su experiencia de cada una de las partes componentes" (Ingram 19). Si bien esa definición, dada en 1971, descansa en la experiencia del lector — sobre todo de un lector que no precisa-, la de Susan G. Mann, de 1989, acentúa un rasgo propio de los textos que la lectura de varios ciclos confirma: "los cuentos son autosuficientes e interdependientes" (15). No obstante, tanto Ingram (19) como Mann (xi) advierten que en unos libros la independencia de los cuentos puede dominar sobre la unidad del todo, en tanto que en otros puede ocurrir lo contrario, además de darse otras variantes: "Si pintáramos el panorama de los ciclos cuentísticos como un espectro, el límite de un extremo del espectro sería la 'mera' colección de cuentos inconexos, mientras que el límite del otro extremo sería la novela" (Ingram 14)); observación con la que en lo esencial coincide J. Gerald Kennedy luego de valorar una serie de ejemplos en los que se muestran "varios grados de aparente organización y cohesión" (viii).

Margaret Dunn y Ann Morris, optando por una etiqueta diferente — novela compuesta_, que enfatiza la unidad frente a la fragmentación, proponen la siguiente definición: "La novela compuesta es una obra literaria compuesta de textos más breves que — aunque individualmente completos y autónomos — están interrelacionados en un todo coherente según uno o más principios organizadores" (2). Por su parte, Gabriela Mora, quien ha estudiado ciclos cuentísticos hispanoamericanos bajo una denominación —-"serie o colección integrada” (114) — que considera más acertada que otras, confirma los rasgos básicos de una obra de esta índole al aseverar: 
"Llamamos integrada a la colección de cuentos que presenta paradigmas de relación entre los diversos relatos, para distinguirla de otra de tipo ‘misceláneo' en que dicha relación no existe” (113). Por su flexibilidad, es la definición que suscribimos, aunque tomemos elementos de otras.

En cuanto a los paradigmas o patrones, Ingram mencionó varios que dividió en "patrones estáticos de estructura externa", tales como "un dispositivo de marco, o una indicación de divisiones por números de capítulos o títulos, o . . un incremento en extensión a medida que la serie progresa (Ein Hungerkünstler) o una alternancia de cuentos y de 'intercapítulos' (In Our Time)"; y "patrones dinámicos de estructura interna", que afectan "temas, leitmotifs, espacios, personajes y estructuras de cuentos individuales" (20-21). Dunn y Morris añaden o precisan elementos: “imágenes repetidas o racimos de imágenes; posiblemente algunos personajes recurrentes, incidentes compartidos y/o un espacio generalmente común; probablemente una o más temáticas comunes; quizá una voz narrativa sostenida y de soporte" (13). Como es evidente — por sus adverbios- que no hay muchas seguridades acerca de cuántos elementos se necesitan para caracterizar un libro de cuentos como una "composite novel", ponen el dedo en un punto neurálgico al preguntarse: “¿Cuánto es suficiente? ¿Cuánto es poco?” (13). Toda vez que ambas estudiosas han apostado por la unidad, sus respuestas apuntan a esta de modo enfático, que cierra mucho el campo y puede limitar innecesariamente las posibilidades de exploración: en una "composite novel" suele haber un espacio, un protagonista único o colectivo, un patrón estructural o temático, o un interés de tipo metaficcional, generalmente más de uno de estos elementos, junto con los procedimientos mencionados arriba (Dunn y Morris 15-16). Pero, otros críticos admiten formas de organización menos restrictivas, y por ellas optamos. Mann, por ejemplo, enumera ciclos unificados por personajes, como "cuentos acerca de la maduración de un protagonista"; o por temas, como el del "aislamiento o fragmentación"; o por otros elementos, como el "arte en general" o "un espacio particular o comunidad" (8-14); Kennedy menciona "ideas, problemas o temas comunes", introducciones, personajes 
recurrentes (viii); James Nagel se limita a "elementos de continuidad en personajes, espacio, acción, imágenes o tema” (15); y Gabriela Mora, tras destacar "la diversidad de maneras de relacionar los cuentos" (114), admite tres grupos de colecciones integradas: las cíclicas, las de tipo secuencial y las de integración restringida, fragmentaria o parcial.

\section{Un ciclo cuentístico}

Veamos entonces algunos elementos que pueden mostrar el carácter de colección integrada de Árboles petrificados. El espacio, rasgo que con más facilidad permite identificar un ciclo cuentístico al ser "la continuidad más persistente en la forma" (Nagel 17) y estar presente en los rasgos mencionados por Ingram, Mann y Dunn-Morris, es México en ocho de los doce cuentos que integran la colección: "La rueda", "La noche de las guitarras rotas", "Garden party", "Griselda", "El último verano", "Óscar", "Estocolmo 3", "El Pabellón del Descanso"; exactamente la Ciudad de México en cinco de ellos ("La rueda", "La noche de las guitarras rotas", "Griselda", "Estocolmo 3", "El Pabellón del Descanso"). ${ }^{4}$ No obstante, es preciso reconocer que, a diferencia de ciclos típicos y de conformación fuertemente espacial, indicada desde sus títulos y ratificada en varios textos, como Winesburg, Ohio de Sherwood Anderson y Dublineses de James Joyce, en el de Dávila la precisión espacial no es enfática y con frecuencia debe deducirse de alguna mención indirecta a un sitio con valor referencial o a conjuntos de sitios, que ayudan a especificar, como: la calle Hamburgo y la tienda Sanborns de la calle Niza, ubicables en la colonia Juárez de la Ciudad de México, en el cuento "La rueda" (21); la calle Estocolmo y la

${ }^{4}$ Los restantes cuentos del libro son: "El patio cuadrado", "La carta", "El abrazo" y "Árboles petrificados".

${ }^{5}$ Puesto que todas las referencias a los cuentos de Árboles petrificados remiten a la misma edición de ese libro de Dávila, en adelante solo se indicará el número de 
propia colonia Juárez, en "Estocolmo 3" (79) o una casa porfiriana y un Sanatorio Inglés, este último probablemente identificable con un hospital inglés de la colonia Anzures o de la Roma, también de la capital federal, en "El Pabellón del Descanso" (89). Aunque es cierto que estas menciones evidencian un cambio de tono respecto a libros anteriores (Gutiérrez 85), siguen siendo escurridizas la mayor parte de las veces, ${ }^{6}$ en consonancia con la tendencia a la interiorización propia de varios representantes de la Generación de 1950 (Valadés 481), en la que suele colocarse a Dávila (Cluff 566, 570; Vidal 624-625). Ello, por demás, es coherente con la poética explícita de la autora, quien a la pregunta de si fue intencional cierto rechazo a "lo mexicano" entre los escritores de su generación, respondió: "A mí en lo particular, siempre me ha preocupado la problemática del ser humano, pero del ser humano no limitado a un determinado sitio geográfico, sino del ser humano universal, como es la angustia, la soledad, la muerte, el amor, la locura" (Lorenzo y Salazar, "Entrevista" 121).

página, y se consignará el apellido de la autora únicamente cuando sea necesario para evitar confusión.

${ }^{6}$ El carácter mexicano en la identificación de los espacios en el resto de los cuentos se deduce de: la mención de un "pasaje que se encuentra detrás de la Catedral" (27), presuntamente la Catedral Metropolitana de la Ciudad de México, y de las palabras de un personaje que habla desde el espacio mexicano, como se deduce del verbo 'venir' y su valor relativo en español (cf. 'venir' en DRAE): "cuando vino a México puso una ferretería en Guadalajara" (29), en "La noche de las guitarras rotas"; de la expresión "aquí en México" (39), puesta en boca de un personaje de "Garden party"; de la ubicación que ofrece un diálogo: “—¿Se fue lejos? / —No, a México solamente" (49), sobreentendiendo que se trata de la capital del país, como además se infiere de la mención de San Jerónimo como lugar cercano (45), en "Griselda"; de la referencia a programas conocidos de la televisión mexicana como Sábados con Saldaña y Nostalgia (58), en "El último verano"; y de la mención de Agua Prieta (69), ciudad o poblado mexicano, como probablemente cercano al pueblo donde se desarrollan los hechos en "Óscar". Por otra parte, puede tenerse en cuenta que la autora afirma que la casa de "El patio cuadrado" se ubica en Pinos, Zacatecas (Herrera 17). 
La época de los acontecimientos no se precisa en ningún caso, como es característico en la prosa de Dávila desde su primer cuento publicado, "El huésped" (1956) (Ocampo 10); pero igualmente, por indicios esparcidos en los textos y dados como conocidos por el lector, puede deducirse que se trata del siglo XX y en particular de mediados de ese siglo. Entre esos indicios hay algunos que, teniendo en cuenta la fecha de publicación del libro como límite convencional más reciente o terminus ad quem (1977), acotan el desarrollo de sus acontecimientos a lapsos breves, como una referencia, en "La rueda" (21), al Sanborns de Niza, inaugurado en 1960 (cf. Grupo Sanborns) y en moda en esa década - lo cual puede apreciarse en otras obras literarias (Zapata 40, 47) — y otra, en "El último verano" (58), al programa televisivo Sábados con Saldaña, vigente en las décadas de 1970 y de 1980 (Cruz Bárcenas y Baños). Pero la mayoría son referentes que indican lapsos temporales amplios, como en "La noche de las guitarras rotas" (28) la mención de La montaña mágica de Thomas Mann, publicada en 1924 y famosa después del otorgamiento del Premio Nobel de Literatura a su autor en 1929; o la televisión en "La carta" (74), servicio que en su uso comercial estuvo disponible en la capital mexicana después de 1950; o vehículos como el coche y el autobús en un pueblo de provincia en "Óscar" (61), lo que sitúa la trama sin duda en el siglo XX; u otros más curiosos como —en "Garden party" (39) — un vestido del diseñador español Cristóbal Balenciaga (1895-1972), activo en París desde 1937, pero cuyo estilo "se impuso en la moda internacional en la década de 1950” (Enciclopedia Hispánica 86). El conjunto de las fechas habla de un México en general moderno, en pleno siglo XX.

Si bien la persona gramatical en que están narrados los cuentos puede variar (primera o tercera), como también difiere de un texto a otro el grado de participación del narrador en la trama, la focalización interna fija es una constante, no observada solo en un cuento, "Garden party"; y aun en él puede identificarse como tendencia a relatar desde el mundo interior del protagonista, Rogelio, que es la única zona que atisbamos. Esa focalización es en buena medida responsable de las limitaciones cognitivas — a veces severas - que como lectores experimentamos para imaginar los mundos de esas 
ficciones. En "El patio cuadrado", no sabemos quién es el Horacio que acompaña a la narradora-protagonista ni quién es el suicida, ni por qué si Horacio ha subido, supuestamente a impedir que el otro se arroje, es él mismo quien al final "se precipitó al vacío" (12); ambos hombres son abandonados poco después por la mirada de la narradora y no sabemos más de ellos. Tampoco sabemos quién es el joven, llamado Marcos, que persigue a la narradora-protagonista de "La rueda" ni — aunque sea intrascendente para entender la historia- conocemos más de Juana o de Teresa que lo que la narradora cuenta de ellas; es su perspectiva y el nivel de conocimientos que ella decide exponer lo único que nos llega. Y así sucesivamente pasará en los demás cuentos. Los narradores dan acceso solo a una pequeña sección de los mundos imaginados (el de Shábada en "La noche de las guitarras rotas", el de la remitente anónima en "La carta", el de la visitante anónima en "Estocolmo 3", el de la amante anónima en "Árboles petrificados") o de los mundos de uno o dos personajes (Martha y Griselda en "Griselda", la mujer encinta de "El último verano", Mónica en "Óscar", Angelina en "El Pabellón del Descanso", Marina en "El abrazo") y no sabemos más.

La afinidad más visible es la que atañe a los personajes, también mencionados en las teorías de Ingram, Mann, Dunn-Morris y Kennedy. Aunque en este libro no haya personajes recurrentes entre un cuento y otro, a lo largo de la mayoría de los cuentos se repite un tipo de protagonista: casi todos son mujeres, en la mayor parte de los casos son anónimas y, si atendemos a una dicotomía de base funcional, llama la atención que casi todas son víctimas o pacientes, según se utilice la nomenclatura de Vladímir Propp o la de Claude Bremond, respectivamente. ${ }^{7}$ Cabe advertir que, aunque esa

\footnotetext{
${ }^{7}$ Respecto a estos conceptos, cabe recordar que Propp los caracterizó como sigue: "The hero of the tale may be one of two types: (1) if a young girl is kidnapped, and disappears from the horizon of her father (and that of the listener), and if Iván goes off in search of her, then the hero of the tale is Iván and not the kidnapped girl. Heroes of this type may be termed seekers. (2) If a young girl or boy is seized or driven out, and the thread of the narrative is linked to his or her fate and not to those who remain behind, then the hero of the tale is
} 
clasificación fue propuesta en el nivel de las funciones por Propp, su valor puede extenderse - como es ampliamente sabido- hasta trascender el corpus folclórico que le sirvió de punto de partida.

Son pacientes o víctimas durante alguna parte de la historia las protagonistas de los siguientes cuentos: "El patio cuadrado", "La rueda", "La noche de las guitarras rotas", "Griselda", "El último verano", "Óscar", "Estocolmo 3", "El Pabellón del Descanso”, "El abrazo" y "Árboles petrificados". Nuevamente "Garden party" es la excepción, con un protagonista hombre, y estas rarezas dentro del conjunto posiblemente obedezcan a que se trata de un cuento de 1956, muy anterior a los demás que acabaron por integrar este libro. No obstante, también su protagonista, Rogelio, está marcado como una víctima, por haber perdido a Celina, y acaba por morir como resultado de esa condición. La búsqueda que podría otorgarle una función de agente al principio de la trama lo lleva a su perdición y a la muerte. En cuanto a las mujeres, la protagonista de "El patio cuadrado" tiene algunos momentos de búsqueda casual dispersos en la trama, pero básicamente es una víctima y como tal termina: tratando de respirar debajo de la tapa de un ataúd; la de "La rueda" comienza con un propósito (acudir a una entrevista), pero es interceptada por un personaje que la hunde en la tierra e insiste en llevarla a la muerte; Shábada, en "La noche...", inicia con una débil búsqueda casual (es una flâneuse), pero es "atacada" por un "monstruo" y termina como víctima; Martha, en "Griselda", debuta como aventurera (es una curiosa cuando entra a la finca con aspecto abandonado), es atacada por el "monstruo" representado por Griselda y termina como víctima, mientras huye; la de "El último verano" es

the seized or banished boy or girl. There are no seekers in such tales. Heroes of this variety may be called victimized heroes" (36). Para el análisis de los cuentos de Dávila, estos conceptos se utilizan de modo aproximado, en lo que pueden tener de equivalentes las situaciones (alguien que se define por buscar o por ser objeto de una amenaza o ataque), pues no hay raptores ni raptados. Por su parte, Bremond, quien no los vincula a una función de héroe o protagonista, distingue los roles de agente y de paciente en el relato: "les patients, affectés par des processus modificateurs ou conservateurs, et les agents, initiateurs de ces processus" (134). 
presentada como una mujer derrotada desde el principio y su embarazo solo la convertirá en víctima de un posible sentimiento de culpa y de terrores que la llevan al suicidio; Mónica, en "Óscar", parecía efectuar un desplazamiento que podría mostrarla como agente, en busca de algo, pero en realidad está regresando a un espacio dominado por otra figura monstruosa (la de su hermano Óscar) y será objeto de sus ataques de furia y de una agresión casi mortal en el clímax del cuento; la de "Estocolmo 3" también es presentada como agente o buscadora al inicio (va a visitar a unos amigos), pero es objeto de la aparición de una figura misteriosa que solo ella ve, que la deja en un estado de perturbación y que contribuye a precipitar su alejamiento. Angelina, en "El Pabellón...”, empieza como víctima de una visita familiar desconsiderada y de una enfermedad y, cuando decide tener voluntad para lograr algo, es para avanzar hacia su muerte; también Marina, en "El abrazo", comienza como víctima de su propia suerte, como una mujer solitaria, triste, que siente el peso de su pasado; y la protagonista de "Árboles petrificados" comienza en la trama de modo muy similar a Marina, hundida en la soledad y en el recuerdo, como esposa de un hombre al que no tolera y, sin embargo, debe aceptar en su lecho.

En once de los doce cuentos, puede advertirse o al menos postularse una relación conflictiva entre el presente y el pasado del protagonista, en este caso, la excepción, sin embargo, no es "Garden party", sino "La noche de las guitarras rotas". No obstante, antes de continuar con el desarrollo de este tema, notemos que todas estas afinidades deberían ser suficientes para demostrar que Árboles petrificados es un ciclo cuentístico. Según la clasificación genética de Ingram, es un ciclo arreglado: "un ciclo arreglado [an arranged cycle] consta de cuentos que un autor o editor-autor ha juntado para iluminar o destacar unos con otros por yuxtaposición o asociación" (Ingram 17-18), y varios de los cuentos de Árboles petrificados se publicaron de manera independiente antes de su compilación definitiva. ${ }^{8}$ Según la tipología de Mora, se trata de una colección de integra-

${ }^{8}$ Por ejemplo, ya se ha indicado que "Garden party" se publicó en 1956 con 
ción restringida, fragmentaria o parcial porque en ella hay "algunos cuentos que parecen no estar relacionados con el resto" (128), (sobre todo uno, ya mencionado varias veces: "Garden party").

\section{La búsqueda de la libertad}

Establecido el carácter de ciclo cuentístico de este libro, veamos la forma en que la relación entre el presente y el pasado de los protagonistas se va perfilando como un tema axial. El primer cuento, "El patio cuadrado", está compuesto por medio de la yuxtaposición de secuencias narrativas en las cuales una mujer anónima experimenta temores frente a: 1) un desconocido que intenta suicidarse; 2) una muerta llamada Olivia; 3) un hombre con un cuchillo que la persigue en sueños y el polvo negro de las alas de unas mariposas, mientras habla con unos lectores del libro La interpretación de los sueños, de Freud; y 4) una superficie sólida, como la tapa de un sarcófago, que le impide regresar a respirar, tras haberse arrojado a una piscina, en una librería o biblioteca donde solicita un ejemplar del Rabinal Achí. Sabemos que es la protagonista solo porque su presencia sirve para unir los segmentos a modo de secuencia y porque su declaración de efectuar un movimiento de retroceso al final de cada segmento hace avanzar la acción. No obstante, su frase "yo comencé a retroceder" es ambigua: puede significar que se interna en las habitaciones de la casa donde tienen lugar los extraños hechos, alejándose del patio en movimiento de retroceso, o que se aleja de la escena inicial del suicida tanto en el espacio como en el tiempo, hacia habitaciones que podrían ubicarse en otras épocas. Varios pasajes sugieren que podría tratarse de un relato onírico, por la ausencia de una causalidad realista o incluso fantástica en el encadenamiento de las acciones,

el título de "Garden Party del olvidado", en Estaciones, no. 3, pp. 375-78; “Árboles petrificados” se publicó en Diálogos, no. 6, 1966, pp. 15-16 y en Zona Franca, no. 53, 1968, pp. 14-16; y "El patio cuadrado" en La Vida Literaria, no. 28, 1977, pp. 4-8 (Ocampo 10). 
por la referencia al clásico de Freud o por el valor quizá simbólico de esa búsqueda de una obra primigenia como el Rabinal Achí dentro de un estanque de agua, en lo más profundo del recorrido. Pero eso no aclara el sentido en el cual podría entenderse el retroceso.

En el segundo cuento, "La rueda", otra mujer anónima sale de desayunar del restaurant de un Sanborns ubicado en lo que podemos identificar como una zona céntrica de la Ciudad de México. Mientras espera la hora de una cita, pasea y siente la presencia de un joven que identifica como Marcos. Huye de él, presa del terror, pero en la huida ambos caen por un abismo que indica una ruptura con el referente mencionado, y ella le reprocha — sin hablar- que la persiga y la quiera llevar a la muerte. Poco a poco empieza a escuchar los ruidos de un timbre y despierta, en su habitación, donde no hay Marcos ni peligros, sino su empleada doméstica, que le ofrece té y vida cotidiana, normal. La mujer se prepara para ir a desayunar con una amiga en el mismo Sanborns de la calle Niza del sueño y allí llega, conversa animadamente, sale a una cita y siente la proximidad de un joven, Marcos. El texto termina con tres puntos suspensivos que sugieren el reinicio de la pesadilla circular, ciclo que nos dificulta conocer los límites de la vigilia y el sueño. Pero, sobre todo, a los fines que aquí interesan, el cuento permite identificar una oposición entre un presente tranquilo, de vida cotidiana, de rutina grata en una casa de clase media y un pasado tormentoso, de un amor que se resiste a aceptar su muerte y que se erige como amenaza.

En una lectura sucesiva, ambas protagonistas, mujeres y víctimas, podrían tener un problema similar: una relación amorosa, con Horacio en "El patio cuadrado", con Marcos en "La rueda"; un final con muerte, por suicidio o por accidente del hombre; un pasado que se niega a aceptar su final y amenaza con absorber y aniquilar a la sobreviviente. En este sentido, "El patio cuadrado" podría precisarse como la historia de un retroceso en el espacio-tiempo y no únicamente en el espacio, y estaría presentando uno de los temas medulares de la colección, aunque para saberlo haya que empezar a adentrarse en ella y luego "mirar atrás". Desde luego, proponer esta interpretación no implica desconocer otras que pudieran hacerse de ese cuento como una obra autónoma —una lectura psicoanalítica, 
por ejemplo, cosa que también puede ser-; pero su consideración desde este punto de vista al menos ofrece la posibilidad de adjudicarle sentidos partiendo de otras piezas cercanas, pertenecientes a la propia autora y a un contexto inmediato.

Si en la continuación de la lectura omitimos los cuentos "La noche de las guitarras rotas" y "Garden party", en los que la postulación de ese conflicto implicaría análisis extensos, los que les siguen, "Griselda", "El último verano", "Oscar", "La carta", "Estocolmo 3" y "El Pabellón del Descanso", son ejemplos bastante claros de ese significado amenazador y hasta destructivo que porta el pasado para una serie de mujeres. Para poner un solo ejemplo, en "Griselda", tanto la protagonista, la joven Martha, como la enigmática señora que da título al cuento se sienten vinculadas a un pasado en el cual dos hombres murieron: Martha pudo reconstruir su vida con otro, en tanto que Griselda quedó presa de su antiguo amor, a quien le ofrendó sus ojos (se los sacó, se vació las cuencas, y los arrojó a un estanque). Griselda, incluso, parece una muerta, alguien que regresa a su vieja casa solo para recordar a su difunto esposo, aunque eso no se dice en el texto. Martha parece libre de ese pasado melancólico porque tiene un segundo novio; pero el hecho de ceder a la tentación que sintió por un espacio claramente caracterizado como abandonado y siniestro, cuya vegetación viciosa y mansión desierta son signos de una posible regresión (Vax 33-34), indica que su pasado la asedia de algún modo, como asedia a un personaje solo referido, su madre, que la ha llevado a San Jerónimo, cerca de la Ciudad de México, por el mismo motivo: porque fue donde falleció su padre.

El cuento que sigue, "El abrazo", da una versión diferente de esa relación temporal. En él, Marina es una mujer presentada como protagonista paciente, víctima tanto de su pasado como de su presente: "sentía el peso de un pasado plenamente vivido, y la soledad presente que la envolvía" (237), pero pasa a comportarse como agente al permitirse tener un deseo, el de ver al hombre al que amó, muerto años atrás en un accidente: "sintió una imperiosa necesidad de verlo" (239). La noche avanzada, una tempestad, un corte súbito de electricidad y ruidos que pueden entenderse ambiguamente con- 
forman la atmósfera que permite la aparición del hombre o lo que como tal Marina percibió, pues la perspectiva narrativa no permite hacer esa distinción. En todo caso, él, como fantasma que conoce el decorum, no habla, en tanto que ella pronuncia un discurso en el que su deseo se muestra colmado: su amante muerto ha regresado, ambos pueden ingresar en un tiempo "sin relojes" (241) que los obliguen a separarse, pues él tenía esposa, y solo falta que ambos se entreguen a un abrazo que sellará su amor para siempre. El abrazo no llega a consumarse, pero la felicidad que ello le promete a la mujer basta para que entendamos que el pasado que regresa puede llenarla de felicidad.

El cuento final vuelve sobre el tema. En "Árboles petrificados", una mujer en condiciones y con rasgos psicológicos y morales similares a los de Marina, se define a sí misma como víctima: "Es de noche, estoy acostada y sola. Todo pesa sobre mí como un aire muerto; las cuatro paredes me caen encima como el silencio y la soledad que me aprisionan. Llueve" (243). La media noche la lleva a recordar a su amante, ausente y probablemente muerto; en cualquier caso, perteneciente a un pasado, aunque no sepamos si cercano o remoto. Los recuerdos son interrumpidos por la llegada de su marido, corpóreo, presente, ${ }^{9}$ que busca comida y canta, que

${ }^{9}$ Estas oposiciones, tan marcadas, y el carácter furtivo de la relación con el hombre en el que la protagonista piensa ("pueden oírnos y descubrir que nos hemos amado apresurada y clandestinamente en esta noche" [106]) dificultan la interpretación según la cual ambos podrían ser el mismo individuo en dos momentos diferentes de la relación, sugerida por una estudiosa: "puede tratarse de la narración del recuerdo de lo que fue la relación en sus inicios con el mismo hombre que hoy desprecia" (García Peña 87). El sentimiento de culpa que la mujer experimenta ("vivimos una noche que no nos pertenece, hemos robado manzanas y nos persiguen" [106]) sería difícil de explicar en esa lectura, a menos que se suponga una relación formal o matrimonial distinta de la presente, respecto de la cual la protagonista y su actual marido hubiesen cometido la falta; pero esto es un elemento que la historia no da argumentos para suplir. Optamos, pues, por una lectura más apegada al texto, como la que efectúa América Luna Martínez, al incluir la mujer de este cuento entre los ejemplos de adulterio (sección "El adulterio de todos tan temido"). 
se acerca a verla mientras ella supuestamente duerme. El pasaje es similar a los de otros cuentos de este y de otros libros de Dávila ("El huésped" de Tiempo destrozado, "Oscar" de Árboles petrificados y "Con los ojos abiertos" del libro homónimo), donde seres monstruosos u hombres agresivos perturban el sueño de una mujer. El momento en el que él se mete en la cama y comienza a acariciarla marca la culminación de lo que significa para ella ese presente: un peso intolerable. Y la imaginación es la vía de escape: ella avanza en un automóvil a toda velocidad a encontrarse con su amante, el espiritual y apasionado que una vez le regaló claveles rojos. Mas, ¿hacia dónde se dirige?: ¿hacia el pasado, donde estaban sus recuerdos, o hacia el futuro? Puesto que este último se hace de deseos, desde un espacio y un tiempo opresivos, puede verse como una prolongación del pasado y, desde este punto de vista, el pasado sería el único refugio. Su amante, dice ella, la ha estado esperando "a través de los días y los años, a pesar de la dicha y la desdicha” (245), y el encuentro se efectúa, los anhelos de pasear tomados de la mano se cumplen, la unión física total se consuma. Pero también, como en "El abrazo", el tiempo se disloca y acaba por anularse: "Vivimos una noche siempre nuestra" (246), lo cual sugiere muerte, como también parece indicarlo la petrificación de los árboles a su alrededor y la suposición de la voz narrativa: "Los árboles que nos rodean están petrificados. Tal vez ya estamos muertos..." (246). A diferencia de "El abrazo", aquí la unión de los amantes se produjo, pero terminó en muerte, en una eternidad fría y rígida como las piedras. El espacio construido con las imágenes y los anhelos del pasado terminó en una forma de la muerte, como quizá era inevitable desde ese lecho, donde las solicitudes carnales del marido asedian a la mujer, que no lo desea.

Puesto que "Árboles petrificados" es la pieza final y le da título al conjunto, tiene un peso fundamental en la articulación del libro como ciclo cuentístico. Si en este cuento el presente es intolerable y la evasión hacia un futuro imaginario, hecho del pasado, conduce a una realización equívoca de la felicidad, que termina en una especie de muerte de los amantes, el balance es desolador: no hay vía de escape; el refugio se convierte en prisión de los amantes; la mujer 
protagonista, víctima, puede huir de un presente agobiante, pero los mundos que construye se convierten en nuevas prisiones.

Este final puede ponerse en relación con los desenlaces de otros cuentos. Puede vincularse, por ejemplo, con el primero del libro, "El patio cuadrado", y su imagen de la protagonista que intentaba recuperar la superficie de la piscina para respirar, luego de haber intentado obtener un libro, imagen explícitamente asociada con la tapa de un sarcófago. Si a la lectura que hemos hecho del retroceso en ese cuento como un valor no solo espacial, sino también temporal, se suma la relación con "Árboles petrificados", la protagonista del primero quedaría más claramente presa no solo en un espacio asfixiante, sino también en un tiempo anterior; y la protagonista de "La rueda" quedaría atrapada, no solo en el espacio del sueño o del vacío que se abre en la calle, sino también en el tiempo del joven muerto; la lectura de la prisión temporal podría sostenerse de manera más firme. La incursión de Martha en una finca abandonada, en "Griselda", sería también y de modo más fundamentado un viaje a un pasado que fue posible para ella, a un pasado en el que se miraría como en un espejo y del que pudo salir, como sale ante el miedo a Griselda, huyendo de pánico. Mónica, en "Óscar”, sería un caso paralelo al anterior: su viaje a la casa familiar es un regreso no solo al espacio original, sino también al tiempo del que una vez salió y del que, en la vez que se puede ver en la ficción, sale milagrosamente: ese pasado es una amenaza mortal. A la protagonista de "El último verano" la relación con el pasado le fue peor: su imagen del feto malogrado terminó por llevarla al suicidio. A las formas de "aprisionamiento" que distinguió Erica Frouman-Smith, como entornos opresivos y falta de "poder, amor, opciones, esperanza" (55), puede añadirse entonces la dimensión del pasado.

El pasado, parece decirnos este libro de Dávila, es amenazador, destructivo, falsa promesa ante un presente casi siempre irrespirable o de bienestar frágil y engañoso. Esto lo descubre una galería de mujeres. Amparo Dávila ha sido clara y enfática al rechazar afinidades con el feminismo; en una entrevista, por ejemplo, declaró: "No creo ser una escritora feminista, definitivamente no" (cit. en Lorenzo y Salazar, "Entrevista” 120). Pero libros como Árboles petri- 
ficados explican el asedio al que la somete la ginocrítica, aun cuando se los analice como aquí se ha hecho, con métodos inmanentistas como el de los ciclos cuentísticos y con conceptos de origen formalista-estructuralista.

Si, ampliando la perspectiva, incorporamos otro componente de género, además del que hemos destacado al hacer un balance de las protagonistas (predominantemente mujeres), podemos notar que en las situaciones presentes que impulsan a las heroínas hacia el pasado o en los espacios pasados donde quedan atrapadas hay motivos vinculables a hombres. Así, en el último segmento de "El patio cuadrado" la protagonista debe arrojarse a la piscina ante la negativa del bibliotecario a darle el libro y como resultado de eso queda atrapada bajo el agua; en "La rueda" ya hemos dicho que Marcos asedia a la protagonista de modo cíclico y obsesivo, y pretende llevarla a su mundo de hombre muerto; en "La noche de las guitarras rotas" un hombre de voz violenta interrumpe la conversación de las dos mujeres en la tienda y los juegos de las dos niñas con los instrumentos musicales; en "Griselda" dos mujeres recuerdan a dos hombres cuyas muertes las absorben hacia el pasado, aun cuando esto ocurra sin intervención de ellos; en "El último verano", la mujer que se descubre tardíamente embarazada rechaza su embarazo entre otras razones por el número de hijos que ya tiene (seis) y por el escaso apoyo que recibe de su esposo, hombre descrito como "seco", "indiferente", "sin aspiraciones" (55); en "Óscar", tanto el padre de Mónica como su hermano enfermo ejercen control sobre el resto de la familia, cada uno a su manera (el padre impone modales en la mesa y Óscar "desde el sótano . . . manejaba la vida de aquella gente" [65]); en "La carta", la voz femenina reprocha desde su muerte a su antiguo amante el haber sido una nulidad la mayor parte del tiempo, el no haber correspondido a sus esfuerzos por lograr una comunicación siquiera; en "El abrazo", Marina recuerda e invoca al hombre muerto del que fue solo amante; y en "Árboles petrificados" la protagonista rechaza al esposo, mientras desea a un amante al que solo parece alcanzar en un mundo de muerte.

Las presencias masculinas en Árboles petrificados suelen ser, pues, o bien amenazadoras, o bien fuerzas que vinculan a las mujeres a 
pasados donde la realización es falaz o imposible; y el pasado puede a menudo ser una cárcel donde un hombre espera a una mujer. Esta no es la opinión personal de la autora sobre los hombres ni la conclusión que se deriva de los análisis de todos sus libros; Dávila ha aclarado al respecto: "también me interesa la problemática del hombre. Por ejemplo, en 'Fragmento de un diario', es un hombre. Tengo varios cuentos, 'Moisés y Gaspar' es un hombre, en 'Final de una lucha' es un hombre" (cit. en Lorenzo y Salazar, "Entrevista" 119). Es, en cambio, una conclusión que puede sacarse del análisis cuantitativo y cualitativo de los cuentos de Árboles petrificados.

\section{Bibliografía}

Álvarez Rivera, Adriana. "Ambigüedad y subversión fantásticas en la narrativa de Amparo Dávila". Tesis doctoral, Universidad de Salamanca, 2016, hdl.handle.net/10366/133062

Baños, Sughey. "Añoranzas y nostalgia por el fallecimiento de Jorge Saldaña". El Universal, 01 noviembre 2014, archivo.eluniversal. com.mx/espectaculos/2014/impreso/anioranzas-y-nostalgia-por-el-fallecimiento-de-jorge-saldania-134326.html

Bremond, Claude. Logique du récit. Éditions du Seuil, 1973.

Cluff, Russell M. "Panorama crítico-histórico del nuevo cuento mexicano”. Pavón, tomo 2, pp. 545-594.

Cruz Bárcenas, Arturo. "Murió Jorge Saldaña, periodista crítico con 'récord de censura"'. La Jornada, 1 noviembre 2014, www.jornada.unam.mx/2014/11/01/espectaculos/a07n1esp\#texto

Dávila, Amparo. Árboles petrificados. Edición conmemorativa, editado por Jonathan Minila, Secretaría de Cultura / Nitro Press, 2016.

Dunn, Maggie y Ann Morris. The Composite Novel: The short story cycle in transition. Twayne Publishers / Maxwell Macmillan Canada, 1995.

Enciclopedia Hispánica: Micropedia. Vol. 1. Encyclopaedia Britannica Publishers, 1991-1992. 
Frouman-Smith, Érica. "Patterns of Female Entrapment and Escape in Three Short Stories by Amparo Dávila". Chasqui, vol. 18, no. 2, 1989, pp. 49-55, www.jstor.org/stable/29740180

García Peña, Lilia Leticia. "La soledad metafísica en Árboles petrificados de Amparo Dávila". Agathos, vol. 9, no. 2, 2018, pp. 85-94, www.agathos-international-review.com/issue9_2/11. Lilia\%20Pena.pdf

Grupo Sanborns. "Acerca de Grupo Sanborns. Historia”. 14 mayo 2018, www.gsanborns.com.mx/historia.html

Gutiérrez, León Guillermo. "Las historias ocultas de Amparo Dávila". Casa del Tiempo, no. 14-15, 2008-2009, pp. 84-86, www. uam.mx/difusion/casadeltiempo/14_15_iv_dic_ene_2009/ casa_del_tiempo_eIV_num14_15_84_86.pdf

Gutiérrez Piña, Claudia L. "Amapolas deshojadas o el horror de la maternidad. «El último verano» de Amparo Dávila". Literatura Mexicana, vol. 29, no. 2, 2018, pp. 133-151, DOI: 10.19130/iifl. litmex.29.2.2018.1133

Herrera, Jorge Luis. "Entre la luz y la sombra. Entrevista con Amparo Dávila”. El Universo del Búho, no. 86, 2007, pp. 14-17. . "Óscar' de Amparo Dávila: el caprichoso dios del patriarca". Texto Crítico, no. 35, 2014, pp. 69-82.

Ingram, Forrest L. Representative Short Story Cycles of the Twentieth Century. Studies in a literary genre. The Hague, 2012.

Kennedy, G. Gerald. "Introduction: The American Short Story Sequence - Definitions and Implications". Modern American Short Story Sequences. Composite fictions and fictive communities, editado por G. Gerald Kennedy, Cambridge University, 1995, pp. vii-xv.

López González, Aralia, et al., coordinadoras. Mujer y literatura mexicana y chicana: Culturas en contacto. Primer Coloquio Fronterizo: 22, 23 y 24 de abril de 1987. El Colegio de México, 1988.

Lorenzo, Jaime y Severino Salazar. "La narrativa de Amparo Dávila". Tema y Variaciones de Literatura, no. 6, 1995, pp. 49-64, hdl. handle.net/11191/1386

. "Entrevista con Amparo Dávila". Tema y Variaciones de Literatura, no. 6, 1995, pp. 115-126, hdl.handle.net/11191/1400 
Luna Chávez, Marisol, y Víctor Díaz Arciniega. "La rutina doméstica como figuración siniestra. Amparo Dávila: su poética del dolor". Sincronia, no. 74, 2018, pp. 205-233, sincronia.cucsh.udg. $\mathrm{mx} / \mathrm{pdf} / 74 / 205-233 \_2018 \mathrm{~b} . p d f$

Luna Martínez, América. "Amparo Dávila o la feminidad contrariada”. Espéculo, no. 39, 2008, www.ucm.es/info/especulo/numero39/adavila.html

Mann, Susan Garland. The Short Story Cycle. A genre companion and reference guide. Greenwood Press, 1989.

Mata Juárez, Oscar. "La mirada deshabitada (la narrativa de Amparo Dávila)". Tema y Variaciones de Literatura, no.12, 2008, pp. 13-24.

Mora, Gabriela. En torno al cuento: de la teoría general y de su práctica en Hispanoamérica. Versión corregida y aumentada, Editorial Danilo Albero Vergara, 1993.

Nagel, James. The Contemporary American Short-Story Cycle. The ethnic resonance of genre. Louisiana State University, 2001.

Ocampo, Aurora M., directora. Diccionario de escritores mexicanos del siglo XX. Desde las generaciones del Ateneo y Novelistas de la Revolución hasta nuestros días. Tomo 2, Universidad Nacional Autónoma de México, 1992.

Ortiz Sánchez, María de Lourdes. Los personajes femeninos en los cuentos de Amparo Dávila. Un enfoque interdisciplinario. Taberna Libraria, 2016.

Pavón, Alfredo, editor. Historia crítica del cuento mexicano del siglo XX. Tomos 1 y 2, Universidad Veracruzana, 2013.

Pita, Beatriz. "La representación de la mujer en dos cuentos de Amparo Dávila". López González et al., Mujery literatura mexicanay chicana. Culturas en contacto: Primer Coloquio Fronterizo: 22, 23 y 24 de abril de 1987, pp. 195-204, www.jstor.org/stable/j.ctvhn096j.23

Propp, Vladimir. Morphology of the Folktale. Traducido por Laurence Scott, segunda edición, University of Texas, 2009.

Reeve, Richard M. "Reseña de Árboles petrificados de Amparo Dávila". Hispania, vol. 63, no. 1, 1980, p. 161, www.jstor.org/stable/340847 
Rivero Romero, Xitlalli. “"Griselda’, de Amparo Dávila: la imposibilidad de escape". Iconicidad de la forma poética: una aproximación cognitiva a cuatro autores mexicanos, Tesis doctoral, Instituto Tecnológico y de Estudios Superiores de Monterrey, 2013, pp. 266-298, repositorio.tec.mx/bitstream/handle/11285/619496/TESIS\% 20Xitlally $\% 20$ Rivero.pdf? sequence $=1$ \&isAllowed $=\mathrm{y}$

Valadés, Edmundo. "Realismo e imaginación". Pavón, tomo 1, pp. 475-482.

Vax, Louis. L'art et la littérature fantastiques. Presses universitaires de France, 1974.

Vidal López-Tormos, Yolanda. "Brevísima historia del cuento mexicano (1955-1995)". Pavón, tomo 2, pp. 619-633.

Zapata, Luis. El vampiro de la colonia Roma. Random House Mondadori, 2008. 